\author{
Abstracta Iranica \\ Abstracta Iranica Revue bibliographique pour le domaine irano-aryen \\ Volume 37-38-39 | 2018 \\ Comptes rendus des publications de 2014-2016
}

\title{
Rüdiger Schmitt. Iranisches Personennamenbuch vol. 2/5: Personennamen in parthischen epigraphischen Quellen
}

Agnes Korn

\section{(2) OpenEdition \\ Journals}

Édition électronique

URL : http://journals.openedition.org/abstractairanica/43013

DOI : 10.4000/abstractairanica.43013

ISBN : 1961-960X

ISSN : 1961-960X

Éditeur :

CNRS (UMR 7528 Mondes iraniens et indiens), Éditions de l'IFRI

\section{Référence électronique}

Agnes Korn, «Rüdiger Schmitt. Iranisches Personennamenbuch vol. 2/5 : Personennamen in parthischen epigraphischen Quellen », Abstracta Iranica [En ligne], Volume 37-38-39 | 2018, document 9, mis en ligne le 30 décembre 2018, consulté le 28 septembre 2020. URL : http://journals.openedition.org/

abstractairanica/43013 ; DOI : https://doi.org/10.4000/abstractairanica.43013

Ce document a été généré automatiquement le 28 septembre 2020.

Tous droits réservés 


\title{
Rüdiger Schmitt. Iranisches Personennamenbuch vol. 2/5: Personennamen in parthischen epigraphischen Quellen
}

\author{
Agnes Korn
}

\section{RÉFÉRENCE}

Rüdiger Schmitt. Iranisches Personennamenbuch vol. 2/5 : Personennamen in parthischen epigraphischen Quellen. Vienne, Österreichische Akademie der Wissenschaften, 2016, 287 p. (Sitzungsberichte der phil.-hist. Klasse 881 / Iranische Onomastik 15).

1 Les données traitées dans le présent ouvrage sont les noms de personnes dans des sources épigraphiques parthes, ce qui inclut quelques noms qui ne sont pas d'origine parthe. Pour le présent ouvrage, le corpus comprend non seulement les sources qui constituent la base de Gignoux 1972 (Glossaire des inscriptions pehlevies et parthes. Corpus Inscriptionum Iranicarum Suppl. 1, Londres, SOAS), c.-à-d. les inscriptions sur rocher, les inscriptions / graffiti de Doura Europos, le parchemin parthe d'Awroman et les ostraca de Nisa, mais aussi des inscriptions sur monnaies et sceaux, bulles, vases etc., donc grosso modo tout ce dont on dispose en langue parthe à l'exclusion des textes littéraires. Le traitement des noms de personnes dans les sources épigraphiques parthes se justifie par ailleurs pleinement par le fait que celles-ci contiennent de très nombreux noms propres, et en effet par ex. sur les ostraca de Nisa, les noms constituent une partie majeure des textes (cp. le glossaire pp. 184-208 de l'édition des ostraca de Nisa par Igor Diakonoff \& Vladimir Livshits 2001: Parthian Economic Documents from Nisa: Texts I. Corpus Inscriptionum Iranicarum II/II/I, Londres, SOAS).

2 La définition de "noms de personnes » adoptée par l'A. inclut des noms personnels et les noms de famille. Sont également inclus des noms de personnes contenus dans des 
noms de lieux comme les domaines viticoles dans les ostraca de Nisa, par ex. prgzykn, qui est apparemment dérivé d'une personne au nom de Fragaz / Pargaz ( ?).

3 La partie principale (p. 33-252) contient donc ce corpus sous forme de 622 entrées dont la structure s'inscrit dans le format général du projet de l'Iranisches Personnennamenbuch (https://www.oeaw.ac.at/iran/forschung/sprachwissenschaftonomastik/iranischespersonennamenbuch/). Chaque entrée est composée des sections B (liste complète des attestations), $\mathbf{P}$ (informations disponibles sur la/les personne(s) portant ce nom) et $\mathbf{D}$ (analyse morphologique et étymologique), suivies par des références pertinentes. L'ouvrage s'achève avec les indexes des noms traités (p. 253), un index inverse (p. 259) et un index des mots en d'autres langues mentionnés dans les entrées.

4 Il faut souligner que les années qui se sont écoulées depuis la publication de Gignoux 1972 ont apporté non seulement de nouveaux travaux et des connaissances nouvelles sur des sources connues, mais également de nouvelles éditions de textes, notamment d'objets trouvés entre-temps. Aussi, Gignoux 1972 constitue-t-il davantage un glossaire plus qu'une analyse linguistique. Le dernier traitement avec analyse approfondie des noms est donc celui par Justi 1895 (Iranisches Namenbuch, Marburg, Elwert), qui est évidemment dépassé en ce qui concerne les sources disponibles et leur analyse. Le présent ouvrage, tout en traitant un corpus difficile et parfois un peu ingrat, offre donc une contribution importante à l'onomastique du moyen-iranien.

\section{AUTEURS}

\section{AGNES KORN}

CNRS, Mondes iranien et indien, Paris 